\title{
Ambiência e Formação de Grupo em Programas de Caminhada
}

\section{Ambiance and Group Formation in Walking Programs}

Marcos Warschauer

Mestre em Educação Física. Consultor do programa "Caminhando para a Saúde".

Endereço: Av. Av. Washington Luis, 546, ap. 131, CEP $11055^{-000,}$ Santos, SP, Brasil.

E-mail: marcoswarœusp.br

Lourdes D'Urso

Fonoaudióloga. Especialista em Saúde da Prefeitura de São Paulo.

Endereço: Rua Dom Antonio Barreiros, 73, ap. 63, CEP 04134-090, São Paulo, SP, Brasil.

E-mail: lourdesdurso®yahoo.com.br

\section{Resumo}

O presente relato discute os conceitos de ambiência e formação de grupo por intermédio de duas experiências com grupos de caminhada desenvolvidos na Atenção Básica: o programa "Caminhando para a Saúde", em Santo André (SP), e o grupo da Unidade de Saúde Jardim Seckler, em São Paulo (SP). Ambas as experiências trabalham com a concepção de prática corporal, que amplia o conceito de atividade física ao colocar o sujeito no centro das ações, e têm como principal enfoque a promoção da saúde. A análise do processo de implementação desses programas destaca a ambiência e a formação de grupo como fatores fundamentais para a adesão à prática. 0 conceito de ambiência é composto de três eixos: a confortabilidade, o espaço como forma de produção de subjetividade e como instrumento facilitador de mudanças no processo de trabalho. Os dispositivos grupais promovem ações de cidadania, priorizando a solidariedade, a comunicação e os relacionamentos pessoais. Esses dois conceitos podem estar correlacionados e viabilizar outras maneiras para a implementação e o desenvolvimento de grupos de caminhada.

Palavras-chave: Formação de grupo; Práticas corporais; Promoção da saúde; Ambiência. 


\section{Abstract}

The present report discusses the concepts of ambiance and group formation by means of two experiences with walking groups developed in Primary Care: the program "Walking for Health", in the city of Santo André, state of São Paulo, and the group of the Jardim Seckler Health Unit, in the city of São Paulo, state of São Paulo. Both experiences were developed using the body practice concept, which goes beyond the concept of physical activity, placing the person at the center of his/her own actions. The experiences' main focus is health promotion. Ambiance and group formation are fundamental factors to adhere to the walking practice. The ambiance concept is formed by three axes: comfortability, space as a way to produce subjectivity and as an instrument that facilitates change in the work process. Group activities promote citizenship actions, prioritizing solidarity, communication and personal relationships. These two concepts, ambiance and group formation, may be related and perhaps they enable other ways to implement and develop walking groups.

Keywords: Group Formation; Body Practices; Health Promotion; Ambiance.
O conceito de ambiência é composto de três eixos: a confortabilidade, o espaço como forma de produção de subjetividade e como instrumento facilitador de mudanças no processo de trabalho. Os dispositivos grupais promovem ações de cidadania, priorizando a solidariedade, a comunicação e os relacionamentos pessoais. Esses dois conceitos podem estar correlacionados e viabilizar outras maneiras para a implementação e o desenvolvimento de grupos de caminhada.

\section{Caracterização do Problema}

Pesquisas sobre os benefícios da atividade física para a saúde são amplamente divulgadas pela mídia. Porém, em sua maioria, esses trabalhos fundamentam-se em uma perspectiva biologicista, na qual a saúde restringese à ausência de doença e a atividade física é vista como sinônimo de gasto de energia. No nosso entendimento, pensar, discutir e promover saúde através de práticas corporais deve se distanciar dessa concepção hegemônica, ao colocar o indivíduo no centro das ações, incorporando elementos das ciências humanas e sociais.

Impulsionadas pela publicação da Política Nacional de Promoção da Saúde, as práticas corporais passaram a ocupar um lugar de destaque dentro do Sistema Público de Saúde. Entretanto, muitos são os problemas para a sua implementação e incorporação à rotina da Atenção Básica. Um deles diz respeito aos conteúdos, pois, na maioria das vezes, privilegia-se o fazer a atividade física e pouco se explora outras dimensões da relação entre profissional e comunidade (Carvalho, 2006), o que torna as práticas corporais distantes da realidade dos usuários, dos profissionais e dos diferentes setores que compõem a administração pública. Outra dificuldade diz respeito à organização dos grupos, pois, muitas vezes, são formados com enfoque nas doenças, o que pouco incentiva a dimensão subjetiva e educativa da ação (Warschauer, 2008). Além disso, a visão de que as práticas corporais precisam, necessariamente, de ambientes apropriados e de materiais específicos desencorajam usuários e profissionais na implementação de grupos como os de caminhada. 


\section{Descrição das Experiências}

O programa "Caminhando para a Saúde" começou em 2003, por meio de uma ação intersetorial entre o Departamento de Lazer e a Secretaria de Saúde de Santo André, em São Paulo, com a perspectiva de melhorar a autonomia e a condição física das pessoas, de despertar o prazer em caminhar mesmo fora do programa, além de aumentar o vínculo dos participantes com as Unidades de Saúde (US).

Inicialmente, o programa foi implementado com poucos recursos financeiros e de maneira experimental em oito unidades. Com o tempo e a mobilização da comunidade, outros locais passaram a ter o "Caminhando para a Saúde" como prática corporal integrada ao seu cotidiano, abarcando 29 unidades com mais de 1200 participantes por mês.

O grupo de caminhada da Unidade Básica de Saúde Jardim Seckler, localizada na periferia da região Sudeste do Município de São Paulo, ao lado da favela de Heliópolis, teve início no ano de 2007 , motivado pela necessidade de se trabalhar com adultos portadores de doenças crônico-degenerativas, como hipertensão, doenças cardiovasculares, obesidade e diabetes, que têm grande prevalência nesse território. 0 insucesso de experiências anteriores com grupos educativos que privilegiavam a prevenção das doenças levou-nos a pensar em outro viés para se trabalhar os grupos. Assim, o conceito que norteou o grupo de caminhada é o da promoção da saúde, com o objetivo de melhorar a qualidade de vida da população por meio da incorporação de hábitos saudáveis ligados às práticas corporais, além de incentivar o aumento da sociabilidade.

Entretanto, muitas foram as dificuldades encontradas na incorporação desse grupo à rotina da unidade, já que tradicionalmente o usuário não busca a prática corporal nesse local. Uma delas diz respeito à formação do grupo e a sua divulgação, pois não houve sucesso a partir da indicação dos médicos da equipe e nem pela divulgação no mural do usuário. Outra foi a de encontrar local adequado para a prática da caminhada, pelo fato de as ruas do entorno da unidade serem movimentadas e acidentadas.

O que há de comum entre essas duas experiências é a determinação de ir além dos conteúdos da atividade física e do monitoramento físico-biológico, incenti- vando a formação de um grupo social, priorizando a solidariedade e a comunicação interpessoal. Outro ponto importante de destaque é a construção de ações ligadas à promoção da saúde, como passeios, palestras, debates, oficinas de alimentação saudável e encontros em parques públicos. Desse modo, criam-se vínculos não só entre as pessoas, mas com a Unidade e com a comunidade, descobrindo e construindo ações de cidadania.

\section{Lições Aprendidas}

No decorrer do processo de implementação dos programas de caminhada surgiram outros dois conceitos importantes para o desenvolvimento desse trabalho: a formação de grupo e a ambiência.

Para pensar na formação de grupo, apoiamo-nos nos estudos de Pichon-Riviére (2005), que descreve uma situação grupal como um conjunto de pessoas ligadas entre si por constantes de tempo e espaço, articuladas por mútua representação interna, tendo como característica importante para a sua finalidade a proposição explícita ou implícita de uma tarefa.

Constituir grupos a partir dos encontros entre os interessados na prática da caminhada nem sempre é tarefa simples e imediata. Entretanto, sua construção se faz fundamental, pois é justamente por meio dos aspectos operativo e educativo que é possível dar sentido e significado à intervenção e possibilitar uma maior adesão à atividade.

Ambiência é um conceito que se refere não só ao espaço físico, mas também ao social, formado pelas relações interpessoais e profissionais com o intuito de proporcionar atenção acolhedora, resolutiva e humana (Brasil, 2006) e é formada essencialmente por três eixos que não devem ser analisados de forma isolada. 0 primeiro refere-se à confortabilidade, valorizando elementos do ambiente que interagem com as pessoas - cor, cheiro, som, iluminação -, garantindo o bem-estar de todos os envolvidos. Com relação aos grupos de caminhada, a confortabilidade está ligada ao reconhecimento e valorização dos espaços públicos - ruas, praças e parques - para incentivar a convivência e a produção de cuidado em saúde.

O segundo eixo caracteriza o espaço como forma de produção de subjetividade por meio da ação e reflexão 
sobre as atividades desenvolvidas. No caso da caminhada, a ambiência pode favorecer os relacionamentos pessoais, o cuidado com o outro, a corresponsabilidade, a comunicação, entre outros, como na ajuda ao atravessar uma rua ou na conversa sobre situações cotidianas.

O terceiro eixo diz respeito ao espaço como instrumento facilitador de mudanças no processo de trabalho, uma vez que esse eixo se relaciona com a otimização de recursos e com o atendimento dado aos usuários. Dessa forma, pensar o espaço como ferramenta de mudança pode incentivar não só atendimentos mais humanizados, acolhedores e resolutivos, mas também propiciar a construção de espaços mais adequados à realidade de cada local, como o ocorrido na US Jardim Carla, em Santo André, onde o grupo de caminhada se reuniu com a comunidade para reivindicar, com sucesso, a construção de uma pista de caminhada.

No nosso entendimento, os dois conceitos discutidos - formação de grupo e ambiência - são fundamentais para a manutenção e a adesão à prática da caminhada. Além disso, eles podem estar correlacionados e proporcionar outras maneiras para a implementação e desenvolvimento de grupos, afastando-se da concepção hegemônica normalmente adotada. Caminhar em parques arborizados, cercados, seguros e com pistas apropriadas, por exemplo, nem sempre contribui para a formação do grupo e pode até, em determinadas circunstâncias, privilegiar o individualismo. Ao contrário, a caminhada nas ruas, calçadas ou em praças, por ocorrer em local vulnerável, reúne as pessoas, cria codependência e pode favorecer a formação de vínculos entre elas.

A intersetorialidade é outro ponto importante e facilitador da implementação das práticas corporais junto ao Sistema Público de Saúde, como pode ser observado na experiência de Santo André, na qual se estabeleceu uma relação entre a Secretaria de Saúde e o Departamento de Lazer. Nesse caso, houve a incorporação de conteúdos do Lazer - o lúdico, a arte, a música - à visão assistencial e de prevenção de doenças da Saúde, o que contribuiu para repensar a interlocução, a formação dos grupos de caminhada e os conteúdos das práticas corporais de forma menos segmentada e com ênfase no indivíduo.

\section{Recomendações}

Caminhar em parques arborizados, cercados e seguros proporciona conforto e segurança para os praticantes. Porém, os programas de caminhada vinculados às Unidades Básicas de Saúde, muitas vezes, estão distantes desses locais, tornando-se necessário buscar alternativas para esse problema. Uma delas é valorizar a formação de grupo, de modo que os usuários identifiquem seu mundo e suas referências para resgatar o vínculo coparticipativo e atuar no processo da produção de saúde. Nesse sentido, entendemos ser fundamental para os profissionais que trabalham com as práticas corporais, tanto no sistema público como no privado, compreender o conceito e a importância da formação de grupos para a promoção da saúde das pessoas.

Outra questão que surge da nossa experiência é que a formação de grupos heterogêneos, compostos de pessoas de diversas idades, doenças e necessidades, pode favorecer a reflexão, o conhecimento, o debate, a troca de experiências, o cuidado entre todos e propiciar a criação de outras formas de se pensar as práticas corporais no âmbito da saúde.

\section{Referências}

BRASIL. Ministério da Saúde. Secretaria de Atenção à Saúde. Núcleo Técnico da Política Nacional de Humanização. Ambiência. 2. ed. Brasília, DF, 2006.

CARVALHO, Y. M. Promoção da saúde, práticas corporais e atenção básica. In: Revista Brasileira Saúde da Família, Brasília, n. 11, p.33-45, jul./set. 2006.

PICHON-RIVIÉRE, E. O processo grupal. 7.ed. São Paulo: Martins Fontes, 2005.

WARSCHAUER, M. "Lazer e Saúde": as práticas corporais no sistema público de Santo André. 2008. Dissertação (Mestrado em Educação Física) - Escola de Educação Física e Esporte da Universidade de São Paulo, 2008. 